\title{
PARTICLE DEPOSITION IN AIRWAY BIFURCATIONS IN DIFFERENT BREATHING CONDITIONS
}

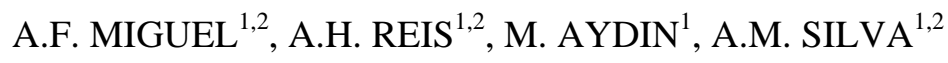 \\ ${ }^{1}$ Geophysics Centre of Évora, Rua Romão Ramalho 59, 7000-671 Évora, Portugal \\ ${ }^{2}$ Department of Physics, University of Évora, Apartado 94, 7002-554 Évora, Portugal
}

Keywords: PARTICLE DEPOSITION, AIRWAY, BREATHING MODE, OBSTRUCTIVE DISEASE.

\section{INTRODUCTION}

During inhaling, the particles transported in the gas mixture may deposit onto the walls of the respiratory tract. Deposition rates depend on particle size, breathing pattern and air duct geometry (Bejan et al. 2004). People suffering from respiratory diseases, such as allergy and asthma and from cardiovascular problems have been identified to be particularly sensitive to inhalation of particulate matter. On the other hand, inhalation route for drug aerosol delivery is a very suitable technique for the treatment of respiratory disorders and other health problems. Toxicology and therapeutic health effects of aerosol particles is strong dependent upon deposition patterns in the respiratory tree.

Multi-dimensional simulations of particle transport and deposition in the respiratory tract have been performed by several authors (see, for example, Bejan et al. 2004). Despite its importance, very few studies deal with the experimental determination of aerosol transport and deposition in bifurcating airways. This is partially due to the difficulty in performing the experiments.

In this paper, particle deposition in a rigid double bifurcation airway is studied experimentally. The effect of particle size and breathing conditions in the deposition are analyzed. Besides, the effect of airway obstruction (local reduction of airway diameter) that can be originated by some respiratory disorders is also studied. The experiments were performed in conditions of humidity near saturation in order to account for the conditions occurring in the respiratory tree (Bejan et al. 2004).

\section{METHODS}

Air containing particles was forced to flow through a double bifurcation duct model made of glass fibre (Fig. 1). This model is of the same size of the first three bifurcations of the human respiratory tree (Reis et al., 2004). To simulate different breathing modes, a small cylinder with a piston connected to a crankshaft was placed in the inlet of the bifurcation duct. Different breathing frequencies were generated by changing the rotational speed of the crankshaft. Details of setup can be found in Miguel (2003) and Miguel \& Reis (2003). The experiments were performed at a relative humidity of $95 \%( \pm 3 \%)$ that match the conditions in the respiratory tree. To simulate particle deposition in obstructed airways due to chronic obstructive pulmonary diseases, a duct model with a diameter reduction of $50 \%$ in about $20 \%$ of its length was also tested. The results are presented in terms of particle penetration $\left(\mathrm{P}=\mathrm{C}_{\text {dws }} / \mathrm{C}_{\text {ups }}\right)$ which follows from measuring particle concentrations upstream $\left(\mathrm{C}_{\mathrm{ups}}\right)$ and downstream $\left(\mathrm{C}_{\mathrm{dws}}\right)$ of the bifurcation duct .

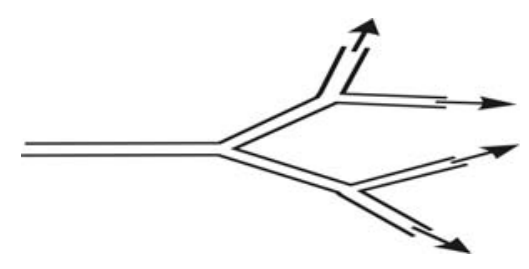

Fig. 1. Schematic representation of the bifurcating duct model 


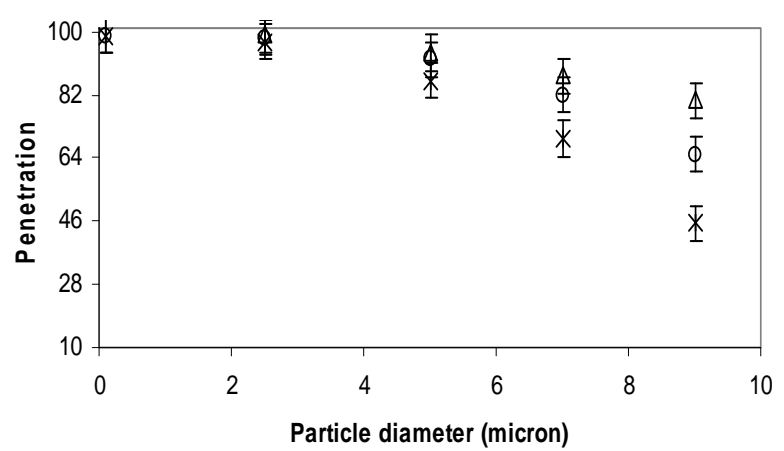

(a)

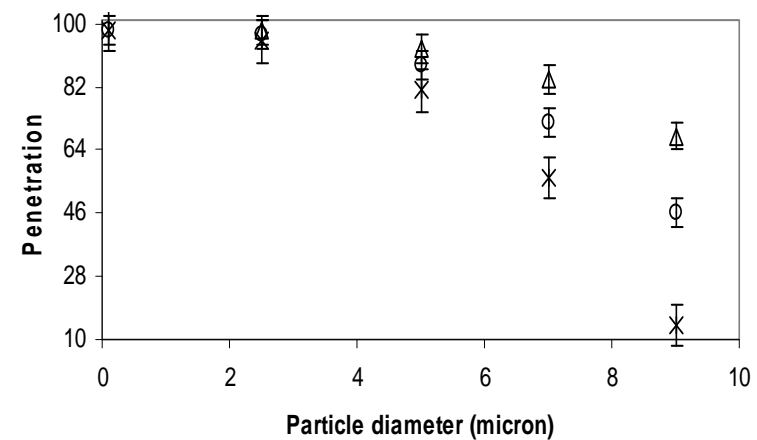

(b)

Fig. 2. Particle penetration at breathing frequencies of $15 / \mathrm{min}$ (a) and 25/min (b), that match resting and light exercise conditions, respectively. (O $1^{\text {st }}$ bifurcation, $\Delta 2^{\text {nd }}$ bifurcation, $x$ entire duct)

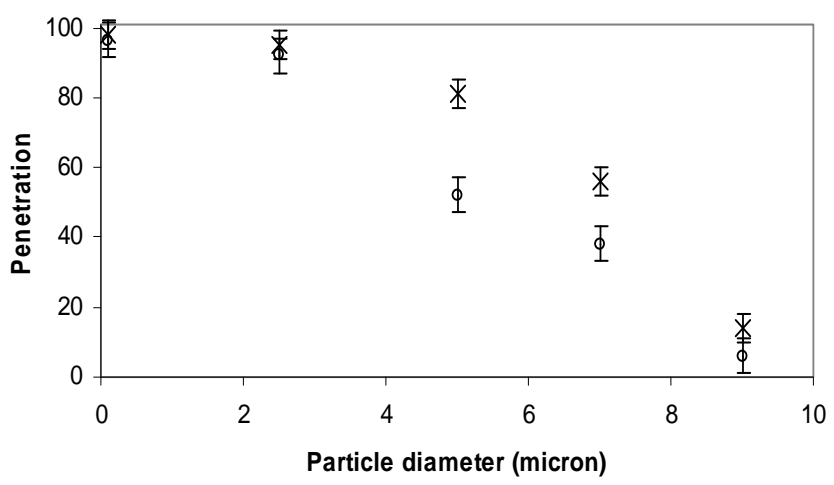

Fig. 3. Particle penetration at breathing frequency of $25 /$ min in a duct model without obstruction $(x)$ and with a reduction of $50 \%$ in diameter over $20 \%$ of its length a $(O)$.

\section{DISCUSSION AND CONCLUSION}

Penetration at breathing frequencies of 15/min and 25/min is depicted in Fig. 2. For particles in the the range $0.1-9 \mu \mathrm{m}$, deposition increases with particle size. This is especially important for diameters ranging from 4.8-9.2 $\mu \mathrm{m}$ (coarse particles). In fact, small particle size seems to be more able to penetrate into the system. Deposits are more significant at the first bifurcation and for the breathing frequency of $25 / \mathrm{min}$ and in particularly for the bigger aerosols. Fig. 3 shows the effect of reduction of duct diameter upon penetration. The results indicate that for coarse particles, deposition should be considerably enhanced in patients with obstructive pulmonary disease as compared to healthy people.

\section{ACKNOWLEDGEMENTS}

This work was supported by Portuguese Foundation for the Science and Technology (FCT) under project POCTI/33012/EME/2000.

\section{REFERENCES}

Bejan, A., Dincer, I., Lorente, S., Miguel, A. F. \& Reis, A. H. (2004). Porous and Complex Flow Structures in Modern Technologies. New York, U.S.A.: Springer-Verlag

Miguel, A. F. (2003). Effect of air humidity on the evolution of permeability and performance of a fibrous filter during loading with hygroscopic and non-hygroscopic particles, J. Aerosol Sc., 34, 783-799.

Miguel, A. F., \& Reis, A. H. (2003). Aerosol particle deposition in a ventilation duct flow, in Proc. of IEEES-1, Izmir (Turkey), 957-961

Reis, A. H., Miguel, A. F., \& Aydin, M. (2004). Constructal theory of flow architecture of the lungs, Medical Physics 31, 1135-1140 